\title{
Prevalence of Under-Nutrition Measured by Composite Index of Anthropometric Failure (CIAF) Among the Bhumij Children of Northern Odisha, India
}

\section{Goswami $\mathbf{M}^{1}$}

${ }^{1}$ Dr. Monali Goswami, Department of Anthropology, University of Calcutta, Kolkata, West Bengal, India.

\author{
Address for correspondence: \\ Dr. Monali Goswami, \\ Assistant Professor \\ Department of Anthropology, \\ University of Calcutta, 35 Ballygunge \\ Circular Road, Kolkata, \\ West Bengal, 700019, India. \\ E-mail: goswami_monali@rediffmail.com
}

\section{Acknowledgements: None}

Funding: Indian Council of Social Science Research, New Delhi, India

Conflict of Interest: None

Permission from IRB: Yes

Ethical dilemmas faced during study: None

\section{How to cite}

Goswami M. Prevalence of UnderNutrition Measured by Composite Index of Anthropometric Failure (CIAF) Among the Bhumij Children of Northern Odisha, India. J Nepal Paediatr Soc 2016;36(1):61-67

doi: http://dx.doi.org/10.3126/jnps.v36i1.14390

This work is licensed under a Creative Commons Attribution 3.0 License.

\begin{abstract}
Introduction: Under-nutrition continues to be a serious health problem among the children in India. In view of the paucity of recent attempts to classify under-nourished children satisfactorily the Composite Index of Anthropometric Failure (CIAF) has been implemented to measure the seriousness and severity of overall under-nutrition in a population. However, there exists scanty information of the prevalence of under-nutrition among the tribal children of Odisha and India. Therefore the objective of the present study is to evaluate the overall prevalence of under-nutrition among the Bhumij children of Northern Odisha, India. Materials and Methods: A total of 136 Bhumij children aged 1 to 6 years (69 boys and 67 girls) were measured. Children were considered as underweight, stunting and wasting if their weight-for-age, height-for-age and weight-for-height Z-scores below -2.0 SD of the National Center for Health Statistics (NCHS) reference data. Severe under-nutrition was assessed as Z-score below -3.0 SD. Results: The overall age and sex combined prevalence of stunting, underweight and wasting recorded was $32.4 \%$, $42.6 \%$ and $25 \%$ respectively, and these rates were considered as high (30-39\%), very high ( $\geq 30 \%)$ and also very high ( $\geq 15 \%)$, respectively. CIAF showed a higher prevalence of undernutrition (54.4\%) i.e., children suffering from anthropometric failure, in comparison to other three conventional indicators (stunting, underweight and wasting). Conclusions: Therefore various nutritional intervention programs can be formulated to improve the nutritional status of the children. It was established herein that CIAF is a better indicator of nutritional status than traditional measures of stunting, underweight and wasting because it differentiates overall and total anthropometric failure.
\end{abstract}

Key words: India, Stunting, tribe, under-nutrition, underweight, wasting, Z -Score.

\section{Introduction}

U nder-nutrition among children is a serious public health problem internationally, especially in developing countries ${ }^{1,2,3}$. In India 
one half of the children under the age of five years are moderately or severely malnourished, $30 \%$ of newborn children are significantly underweight and nearly $60 \%$ of women are anemic ${ }^{4}$. During pre-school age period, children have special nutritional needs because of their extensive growth and development ${ }^{5,6}$. Malnutrition makes a child susceptible to infections and delays recovery, thus increasing mortality and morbidity?

In the last five decades, mortality rates have come down by $50 \%$ and the fertility rate by $40 \%$ but reduction in under-nutrition is only $20 \%$. In spite of the relatively slow reduction in child under-nutrition in India, the country can still accelerate the rate of reduction in childhood under-nutrition and under five mortality rate by ensuing early detection and effective management of both under-nutrition and infections.

Child growth is the universalized tool to assess adequate nutrition, health and development of individual children, and to estimate overall nutritional status and health of populations. Compared to other health assessment tools, measuring child growth is a relatively inexpensive, easy to perform and non-invasive process $^{5,6,8}$.

Three most commonly used internationally recommended indicators are stunting (low height-forage), underweight (low weight-for-age) and wasting (low weight-for-height) $)^{5,6}$.

It has been stated by the development economist Peter Svedberg that conventional indices are not sufficient for measuring the overall prevalence of under-nutrition among young children ${ }^{9}$. He further suggested that if children with wasting, stunting or who are underweight are all considered as undernourished, or to be in a state of "anthropometric failure", a new aggregate indicator is needed, one that incorporates all undernourished children, by their wasted and/or stunted and/or underweight and proposed the construction of a -CIAF. The Composite index of anthropometric failure (CIAF) incorporates all undernourished children in a single category and highlights the severity of a population's overall undernutrition more precisely than the three individual conventional measures. The CIAF has been used and validated by two previous Indian studies $^{11,12}$.

The present study focuses on the CIAF assessment to estimate the overall prevalence of undernutrition among the Bhumij children of Northern Odisha.

\section{Materials \& Methods}

The present study was a cross-sectional study conducted in three villages of Remuna and Nilgiri Blocks of Baleswar District, Northern Odisha, India. The study was carried out from November 2012 to February 2013. A total of 136 preschool children aged 1-6 years (69 boys; 67 girls) were assessed. Data was collected after obtaining necessary approval from the parents, villages and the block authorities. Parents were informed about objectives of the present study and their consent was obtained.

Information on age, gender, weight and height was collected on a structured pre-tested schedule by house to house visit following the interview method and examination. Anthropometric measurements were taken on each subject following the standard techniques ${ }^{12}$. Technical errors of measurement were found to be within reference values ${ }^{13}$. Children were considered as underweight, stunting and wasting if their weightfor-age, height-for-age and weight-for-height Z-scores below -2.0 SD of the National Center for Health Statistics (NCHS) reference data ${ }^{14}$. Severe under-nutrition was assessed as Z-score below -3.0 SD. Thus three commonly used under-nutrition indicators, i.e. stunting (low height-for-age), underweight (low weight-for-age) and wasting (low height-for-age) were used to evaluate the nutritional status of the subjects and CIAF for the total children. The WHO classification was also followed for assessing severity in malnutrition by rate prevalence ranges of these three indicators among children ${ }^{5}$. The classification is shown in table-l. Student's t-test was undertaken to test for sex differences in means of height and weight. Statistical significance was set at $p<0.05$.

After calculating different $Z$ scores the values were then compared to the international cut offs by WHO and number of wasted ( $\mathrm{WHZ}<-2 \mathrm{SD}$ ), underweight (WAZ<-2SD) and stunted (HAZ<-2SD) students were assessed. The children on the basis of the z-score were then categorized as per the subgroups of Svedberg's model in order to arrive at the CIAF to get the overall prevalence of under nutrition $\left(\mathrm{WHO}^{10}\right)$. The z-score for different nutritional indices were calculated in reference to $\mathrm{WHO}$ international guidelines and the prevalence of underweight, stunting and wasting were calculated at cut-off level $<2 \mathrm{SD}$ or $\mathrm{Z}$ - score $<-2\left(\mathrm{WHO}^{10}\right)$. For assessing CIAF, Svedberg's model was used.

For assessing the CIAF, Svedbergs model of six groups of children was used ${ }^{9}$. These groups include children with height and weight appropriate for their 
age (i.e. who are not in anthropometric failure) and also children height and weight for their age are below the norm and thus are experiencing one or more forms of anthropometric failure ${ }^{15}$. These groups are defined in table-2.

The CIAF excludes those children not in anthropometric failure (i.e. group A) and includes all children who have wasting, stunting, or underweight (i.e. group $\mathrm{B}$ to $\mathrm{F}$ ). It therefore provides a single measure to estimate the overall prevalence of under-nutrition. Svedberg originally suggested six sub-groups of anthropometric failure (A to F). However Nandy identified an additional subgroup: one that includes children who are only underweight but are not stunted or wasted $(\text { Group }-\mathrm{Y})^{15}$. Thus, table-2 represents the classification of children with anthropometric failure (CIAF). Another theoretical combination would be "wasted and stunted" but this is physically not possible since a child cannot simultaneously experience stunting and wasting and not being underweight ${ }^{15}$.

The current study uses the Z-score system and the Composite Index of Anthropometric Failure (CIAF) to estimate the magnitude of under-nutrition among 1-6 years Bhumij pre-school children of Northern Odisha, India.

\section{Results}

The mean height and weight of the children are presented in Table-3. There was a significant sex \& age difference in all parameters, i.e. height and weight $(p<0.05)$. It was observed that boys were heavier and taller than girls at all ages.
Table 4 presents the rates of stunting, wasting and underweight among the Bhumij pre-school children. The overall age and sex combined prevalence of stunting, underweight and wasting were $32.4 \%, 42.6 \%$ and $25 \%$ respectively (Fig-2). These rates were high (30-39\%), very high ( $\geq 30 \%)$ and also very high ( $\geq 15 \%)$, respectively, according to $\mathrm{WHO}$ classification of under-nutrition severity (Table-1) ${ }^{5}$. Moreover, maximum prevalence of under-nutrition (underweight, stunting and wasted) was observed among the girls at the age of 2 years, 3 years and 5 years girls respectively (age and sex specific) (Fig-1). There were no significant sex differences except at the age of 1 year, 4 years and 5 years in underweight \& stunting only $(p<0.05)$. Significant age difference was observed among boys in underweight $(p<0.05)$ only. In the present study, the rate of stunting and underweight shows more or less the same prevalence as compared to UNICEF ${ }^{16}$.

Table 5 represents the proportions of children in each of the subgroups. Out of each subgroups (B-Y) with undernourished children, group $D$ children who simultaneously had wasting, stunting \& underweight was the highest (16.2\%). Children who are only wasted (Group B), only stunted (Group F) or only underweight (Group Y) showed lower prevalence of under-nutrition. Children who are stunted as well as underweight (Group E) accounted for $15.4 \%$ and children who are wasting and underweight accounted for $7.4 \%$. Thus, CIAF showed a higher prevalence of under-nutrition (54.4\%) i.e., children suffering from anthropometric failure, in comparison to other three conventional indicators (stunting, underweight \& wasting).

Table 1A: Classification assessment for severity of malnutrition by percentage prevalence ranges (WHO, 1995)

\begin{tabular}{ccccc}
\hline Classification & Low (\%) & Medium (\%) & High (\%) & Very High (\%) \\
\hline Underweight & $<10$ & $10-19$ & $20-29$ & $\geq 30$ \\
Stunting & $<20$ & $20-29$ & $30-39$ & $\geq 40$ \\
Wasting & $<5$ & $5-9$ & $10-14$ & $\geq 15$ \\
\hline
\end{tabular}

Assessment of nutritional status.

Z-scores was calculated following the standard formula:

Z-score $=($ X-Median of NCHS)/Standard deviation of NCHS

Table 1B: Anthropometric Indices and Cut-off Points for Children to Assess the Severity of Malnutrition (According to WHO, 2006)

\begin{tabular}{ccc}
\hline Indicator & Meaning & Cut-off Point \\
\hline Wasting & Low Weight for Height $(\mathrm{WHZ})$ & $<-2 \mathrm{SD}$ \\
\hline Underweight & Low Weight for Age (WAZ) & $<-2 \mathrm{SD}$ \\
\hline Stunting & Low Height for Age (HAZ) & $<-2 S D$ \\
\hline
\end{tabular}


Table 2: Classification of children for the assessment of anthropometric failure (CIAF) according to Nandy et al. (2005).

\begin{tabular}{clccc}
\hline Group name & Description & Wasting & Stunting & Underweight \\
\hline A & No failure & No & No & No \\
B & Wasting only & Yes & No & No \\
C & Wasting \& Underweight & Yes & No & Yes \\
\hline D & Wasting, Stunting \& Underweight & Yes & Yes & Yes \\
\hline E & Stunting \& Underweight & No & Yes & Yes \\
\hline F & Stunting only & No & Yes & No \\
Y & Underweight only & No & No & Yes \\
\hline
\end{tabular}

Table 3: Mean (SD) height and weight of the preschool Bhumij children aged 1-6 years.

\begin{tabular}{ccccccc}
\hline \multirow{2}{*}{ Age (years) } & \multicolumn{3}{c}{ Boys $(\mathbf{n}-69)$} & \multicolumn{3}{c}{ Girls (n-67) } \\
\cline { 2 - 7 } & $\mathbf{n}$ & Height $(\mathbf{c m})$ & Weight $(\mathrm{Kg})$ & $\mathbf{n}$ & Height (cm) & Weight (Kg) \\
\hline 1 & 10 & $71.34(4.01)$ & $8.9(1.30)$ & 7 & $70.84(4.23)$ & $8.6(1.21)$ \\
\hline 2 & 13 & $83.86(4.27)^{\star}$ & $10.2(1.43)$ & 14 & $82.16(4.46)$ & $9.8(1.46)$ \\
\hline 3 & 14 & $90.97(4.63)$ & $12.7(1.61)$ & 11 & $90.31(4.28)$ & $12.2(1.37)$ \\
\hline 4 & 12 & $98.10(4.37)$ & $14.5(1.58)^{\star}$ & 8 & $97.92(4.83)$ & $13.6(1.50)$ \\
\hline 5 & 9 & $106.81(4.06)^{\star}$ & $16.8(1.47)$ & 15 & $105.25(4.60)$ & $16.4(1.87)$ \\
\hline 6 & 11 & $112.73(4.86)$ & $19.6(1.72)$ & 12 & $112.48(4.54)$ & $19.2(1.76)$ \\
\hline
\end{tabular}

Figures in parentheses are standard deviations.

${ }^{*} p<0.05$ significant sex and age differences

Table 4: Prevalence of under-nutrition among the Bhumij children aged (1-6 years)

\begin{tabular}{|c|c|c|c|c|c|c|c|c|c|c|c|c|c|}
\hline \multirow{4}{*}{ Category } & \multicolumn{12}{|c|}{ Age in years } & \multirow{3}{*}{$\begin{array}{c}\text { Overall } \\
\text { (Age \& sex } \\
\text { combined) }\end{array}$} \\
\hline & \multicolumn{2}{|c|}{1} & \multicolumn{2}{|c|}{2} & \multicolumn{2}{|c|}{3} & \multicolumn{2}{|c|}{4} & \multicolumn{2}{|c|}{5} & \multicolumn{2}{|c|}{6} & \\
\hline & Boys & Girls & Boys & Girls & Boys & Girls & Boys & Girls & Boys & Girls & Boys & Girls & \\
\hline & $n-10$ & $n-7$ & $n-13$ & $n-14$ & n-14 & $n-11$ & $n-12$ & $n-8$ & $n-9$ & n-15 & $n-11$ & $n-12$ & $\mathrm{~N}-136$ \\
\hline
\end{tabular}

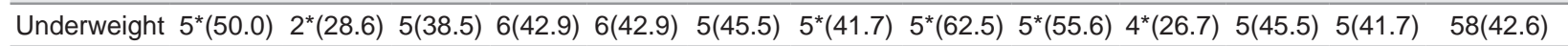

$\begin{array}{llllllllllllll}\text { Stunting } & 3^{*}(30.0) & 3^{*}(42.9) & 4(30.8) & 5(35.7) & 4(23.6) & 4(36.7) & 5^{*}(41.7) & 2^{*}(25.0) & 2^{*}(22.2) & 6 *(40.0) & 3(27.2) & 3(25.0) & 44(32.4)\end{array}$

\begin{tabular}{llllllllllllll} 
Wasting & $2(20.0)$ & $2(28.6)$ & $4(30.8)$ & $3(21.4)$ & $4(28.6)$ & $2(18.1)$ & $2(16.7)$ & $1(12.5)$ & $2(22.2)$ & $5(33.3)$ & $3(27.2)$ & $4(33.3)$ & $34(25.0)$ \\
\hline
\end{tabular}

Figures in parentheses are percentages

* Significant sex differences at $p<0.05$

Table 5: Subgroups of anthropometric failure among the studied children.

\begin{tabular}{|c|c|c|c|c|c|c|c|c|c|c|c|c|c|}
\hline \multirow{4}{*}{ Group } & \multicolumn{12}{|c|}{ Age in years } & \multirow{3}{*}{$\begin{array}{c}\text { Overall } \\
\text { (age \& sex } \\
\text { combined) }\end{array}$} \\
\hline & \multicolumn{2}{|c|}{1 year } & \multicolumn{2}{|c|}{2 year } & \multicolumn{2}{|c|}{3 year } & \multicolumn{2}{|c|}{4 year } & \multicolumn{2}{|c|}{5 year } & \multicolumn{2}{|c|}{6 year } & \\
\hline & Boys & Girls & Boys & Girls & Boys & Girls & Boys & Girls & Boys & Girls & Boys & Girls & \\
\hline & $n-10$ & $n-7$ & $n-13$ & $n-14$ & $n-14$ & $n-11$ & $n-12$ & $n-8$ & $n-9$ & $n-15$ & $n-11$ & $n-12$ & $\mathrm{~N}-136$ \\
\hline A (No Failure) & $5(50.0)$ & $3(42.9)$ & $7(53.8)$ & $6(42.9)$ & $5(35.7)$ & $6(54.5)$ & $4(33.3)$ & $3(37.5)$ & $4(44.4)$ & $8(53.3)$ & $5(45.5)$ & $6(50.0)$ & $62(45.6)$ \\
\hline B (Wasting only) & - & - & $1(7.7)$ & $1(7.1)$ & $2(14.3)$ & - & $2(16.7)$ & - & - & - & $1(9.1)$ & - & $7(5.1)$ \\
\hline $\begin{array}{l}\text { C (Wasting \& } \\
\text { Underweight) }\end{array}$ & $1(10.0)$ & $1(14.3)$ & $1(15.4)$ & - & $2(14.3)$ & $1(9.1)$ & - & $1(12.5)$ & - & $2(13.3)$ & - & $1(8.3)$ & $10(7.4)$ \\
\hline $\begin{array}{l}\text { D (Wasting, } \\
\text { stunting and } \\
\text { underweight) }\end{array}$ & $1(10.0)$ & $1(14.3)$ & $2(15.4)$ & $3(21.4)$ & $1(7.1)$ & $2(18.2)$ & $4(33.3)$ & $1(12.5)$ & $1(11.1)$ & $1(6.7)$ & $3(27.3)$ & $2(16.7)$ & $22(16.2)$ \\
\hline $\begin{array}{l}\text { E (Stunting \& } \\
\text { underweight) }\end{array}$ & $2(20.0)$ & - & $2(15.4)$ & $3(21.4)$ & $3(21.4)$ & $2(18.2)$ & $1(8.3)$ & $1(12.5)$ & $2(22.2)$ & $3(20.0)$ & $2(18.2)$ & - & $21(15.4)$ \\
\hline $\mathrm{F}$ (Stunting only) & - & $2(28.6)$ & - & $1(7.1)$ & $1(7.1)$ & - & $1(8.3)$ & - & - & $1(6.7)$ & - & $1(8.3)$ & $7(5.1)$ \\
\hline $\begin{array}{l}\text { Y (Underweight } \\
\text { only) }\end{array}$ & $1(10.0)$ & - & - & - & - & - & - & $2(25.0)$ & $2(22.2)$ & - & - & $2(16.7)$ & $7(5.1)$ \\
\hline CIAF & $5(50.0)$ & $4(57.1)$ & $6(46.2)$ & $8(57.1)$ & $9(64.3)$ & $5(45.5)$ & $8(66.6)$ & $5(62.5)$ & $5(55.6)$ & $7(46.7)$ & $6(54.5)$ & $6(50.0)$ & $74(54.4)$ \\
\hline
\end{tabular}

Group A indicates normal (No anthropometric failure); N=A+CIAF = Composite Index of Anthropometric Failure

Figures in parentheses are percentages 
Table 6: Prevalence of CIAF in Pre-school children: A comparison with other studies from India.

\begin{tabular}{ccccc}
\hline S. No & Sample Size (n) & Study area & CIAF(\%) & Source \\
\hline 1 & NFHS-2 (98/99) & National Average & 59.8 & Nandy, 2005 \\
\hline 2 & - & Coimbature, Tamil Nadu & 68.6 & Seetharaman et al (2007) \\
\hline 3 & 2016 & Chapra, Nadia, WB & 60.4 & Biswas et al (2009) \\
\hline 4 & 347 & Purulia, WB & 66.3 & Das \& Bose (2009) \\
\hline 5 & - & Arambagh, Hoogly, WB & 73.1 & Mandal \& Bose (2009) \\
\hline 6 & 188 & Bankura, WB & 69.1 & Mukhopadhyay \& Biswas (2011) \\
\hline 7 & 438 & Kashmir, India & 25.58 & Fazili et al (2012) \\
\hline 8 & 225 & Purba Medinipur, WB & 50.2 & Acharya et al (2013) \\
\hline 9 & 136 & Balasore, Odisha & 54.4 & Present Study \\
\hline
\end{tabular}

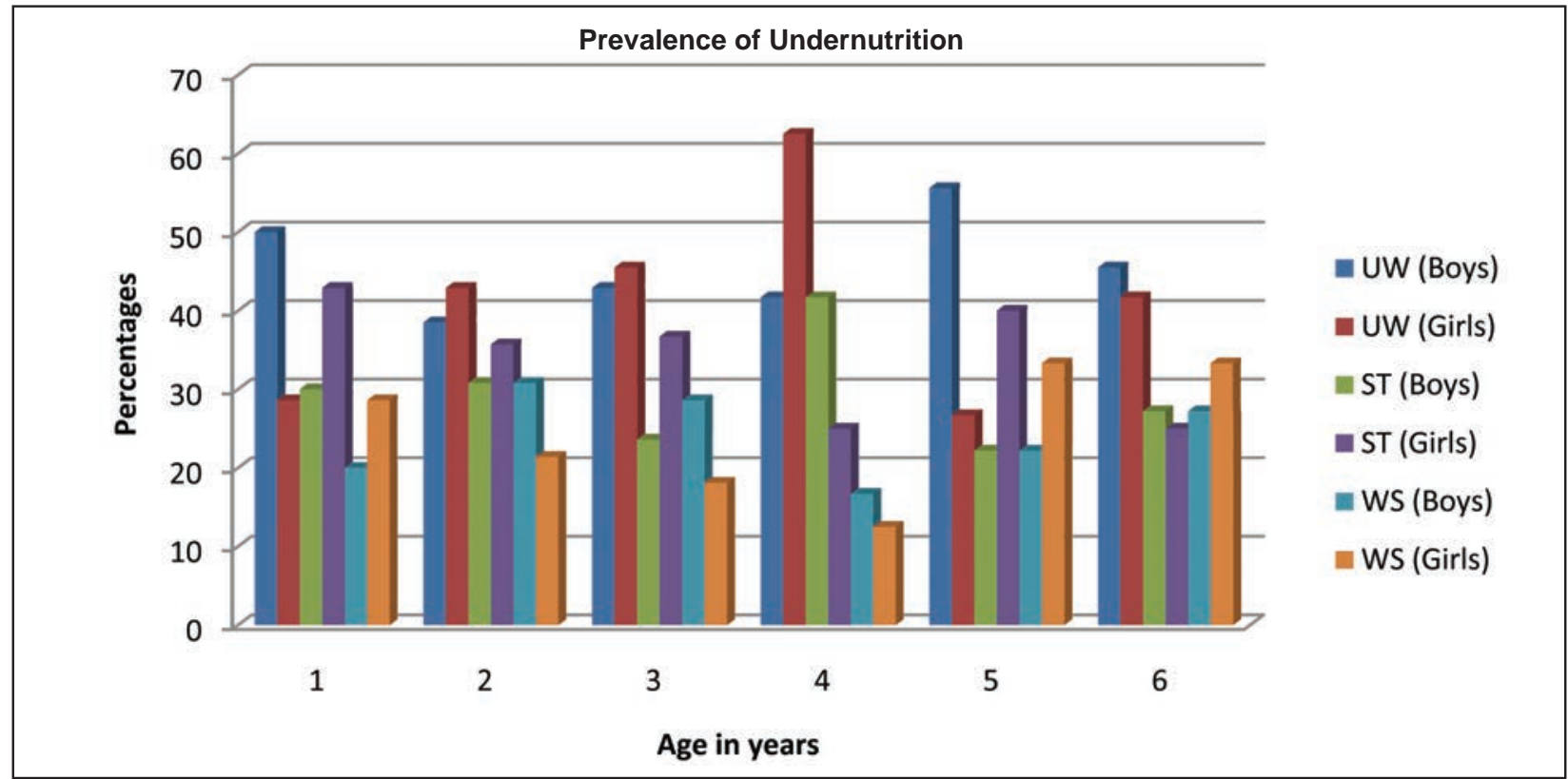

Fig 1: Undernutrition Prevalence (\%) using different indicators

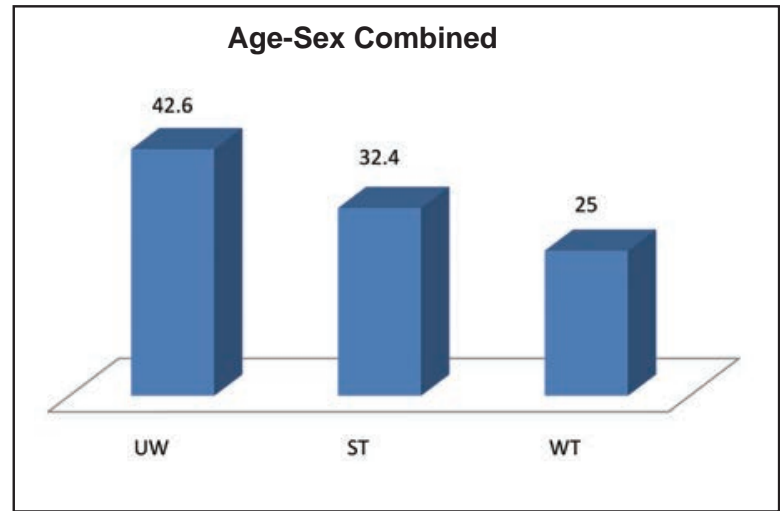

Fig 2: Prevalence of Undernutrion (\%) among the Bhumij Children (Age-Sex Combined)

\section{Discussion}

Malnutrition in children under five years of age is one of the most serious health problems in developing countries $^{17}$. It is also a major cause of child mortality in India, where the World Bank report of 2005 confirmed that 47 percent of Indian children below the age of five

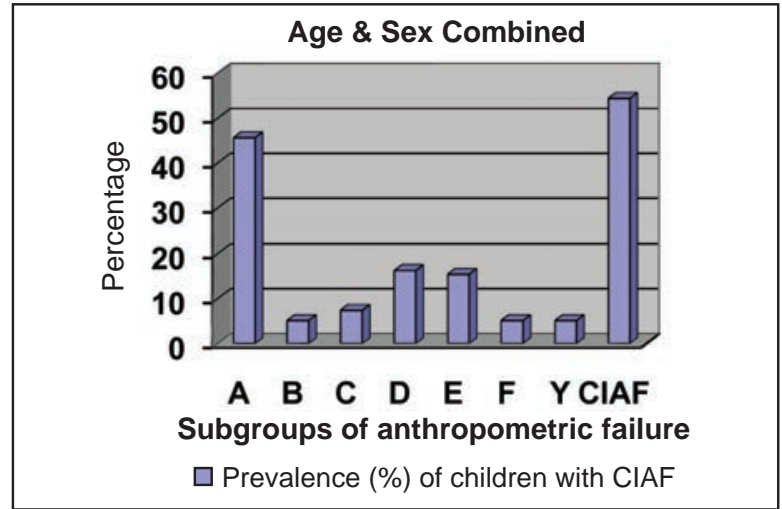

Fig 3: Subgroups of Anthropometric Failure

were malnourished. Further, reported that India has the highest incidence of childhood malnutrition in the world ${ }^{18}$. A recent study has developed a new index i.e. Composite Index of Anthropometric Failure (CIAF) ${ }^{15}$. Studies on health and nutritional assessment have been conducted in different parts of India among the 
tribal \& non-tribal children ${ }^{19,20,21,15,22,23,17,24}$. But nutritional assessment and CIAF anthropometrical data among the tribal children of Northern Odisha was nonexistent or until now it has not been investigated. Therefore the present study was undertaken to evaluate the levels of stunting, underweight and wasting and also to assess the overall prevalence of under-nutrition by using CIAF among the Bhumij tribal children (1-6 years) of Northern Odisha. Very few studies have been reported from India which have dealt with CIAF especially in school going children ${ }^{25}$.

The total burden of malnutrition measured by CIAF in young Indian children is considerably higher. This is the country with largest child population in the world ${ }^{26}$. Nationwide survey showed definite improvement in nutritional profile of Indian children, though the picture is still gloomy ${ }^{27,28}$.

Fig 3 shows that CIAF sub-groups of undernourished children, with $15.3 \%$ having single anthropometric failure (Groups B, F and Y) and 39\% having multiple anthropometric failure (Groups C, D and E). After summation in Groups B-Y, it is found that $54.4 \%$ of the Bhumij children had a high prevalence of undernutrition with some form of anthropometric failure.

The overall prevalence of stunting, underweight and wasting in the present study demonstrated slightly better results (44.2\% stunting, $44.0 \%$ underweight and $15.8 \%$ wasting respectively) compared to the Indian situation $^{17}$. The present study shows more or less the same prevalence $(54.4 \%)$ of overall undernutrition (by CIAF) with the recent study (CIAF-50.2\%) done by $^{29}$ Acharya et al (2013). Most importantly, it must be noted here that the findings of the present study are in accordance with those of, who also reported higher rates of CIAF compared to the other three (Underweight, stunting and wasting) more conventional measures of under-nutrition ${ }^{15,17,25}$. The use of CIAF in the present study establishes that $54.4 \%$ of Bhumij children had some form of anthropometric failures. Although undernutrition measured by CIAF is considerably lower than that recorded in other studies, but this scenario is extremely alarming $30,31,32,15,18,17$. Children with multiple anthropometric failures were more likely to experience ill-health and were at more risk of dying than those with single anthropometric failure ${ }^{36}$.

The findings of widespread prevalence of undernutrition among tribal \& non-tribal children in India were also corroborated in this study (Table-6).

Previous studies from India have recorded the nutritional burden (CIAF) existing among the children. These include Nandy et al (2005) (59.8\%); Seetharaman et al (2007) (68.6\%); Biswas et al (2009) (60.40\%); Das and Bose (2009) (66.3\%); Mondal and Bose (2009) (73.1\%); Mukhopadhyay \& Biswas (2011) (69.1\%); Fazili et al (2012) (25.58\%); Acharya et al (2013) (50.2\%); Present study (2014) (54.4\%) ${ }^{15,17,30,31,16,25,29}$. All these studies found high rates of under-nutrition measured by CIAF. Thus the total burden of malnutrition measured by CIAF in rural and tribal children of India is considerably higher (mostly above 60\%). This situation is not only distressing but very alarming since childhood is the foundation for both physiological \& psychological development.

The present study is limited by its small sample size, being only from one area of Odisha, India. These results may therefore only be representative of a small community and not representative of the state or country. Therefore, to obtain a broader representation, more studies involving CIAF is to be undertaken among children of other tribal populations of not only Odisha but also from different parts of India. These results will not only allow us to compare the rates of three conventional measures of under-nutrition with CIAF, but also helps us to establish the improved effectiveness and use of CIAF.

\section{Conclusion}

The present study establish the overall prevalence of undernutrition using the $\mathbf{Z}$ Score and the composite index of anthropometric failure among the Bhumij children (1-6 years) of Northern Odisha, India. The study reflects that $54.4 \%$ of the children had some form of anthropometric failure and $39 \%$ of the children experienced multiple anthropometric failure. Thus it is concluded that these children are under acute and chronic undernutrition. The present study, by disintegrating the undernourished children into different groups, helps in identifying children with multiple anthropometric failures and these children with multiple anthropometric failures form the priority group for planners and policy makers.

\section{Recommendations}

It is therefore recommended that similar studies should be undertaken using the CIAF assessment among the children of other tribal populations of not only Odisha but also other parts of India. Various valuable nutritional intervention programs can be formulated to improve the nutritional status of the children with a priority towards children with multiple anthropometric failures. Moreover improvement of their nutritional status is of paramount importance from the national public health perspective. 


\section{References}

1. Pelletier DL, Frongillo EA. Changes in child survival are strongly associated with changes in malnutrition in developing countries. J Nutr 2003: 133:107-119.

2. El-Ghannam AR. The global problems of child malnutrition and mortality in different world regions. $J$ Health Soc Policy 2003: 16: 1-26.

3. Staton DM, Harding $\mathrm{M} \mathrm{H}$. Protecting child health worldwide-Implementation is the biggest challenge slowing efforts to reduce childhood morbidity and mortality in developing countries. Pediatr Ann 2004: 33 : 647-655.

4. Govt of India. Economic Survey. 2002-2003: 229-233.

5. World Health Organization. Physical status: the use and interpretation of anthropometry. Technical report series no 854.1995: World Health Organization, Geneva.

6. Lee RD, Nieman DC. Nutritional assessment. New York: 2003: McGraw Hill.

7. Chatterjee S, Saha S. Astudy on knowledge and practice of mothers regarding infant feeding and nutritional status of under-five children attending immunization clinic of a medical college. Internet J Nutrition Wellness 2008:5(1).

8. Blossner M, de Onis M, Uauy R editors. Estimating stunting from underweight survey data- In Bose K: Culture, Ecology, Nutrition, Health and Disease. J Hum Ecol. Spec. 2006:Iss 14: 145-152.

9. Svedberg P. Poverty and undernutrition; theory, measurement and policy. New Delhi:2000: Oxford India Paperbacks.

10. World Health Organization. WHO Child Growth Standards, length/height-for-age, weight-for-length, weight-for-height and body mass index-for-age: methods and development- World Health Organization.2006: Geneva.

11. Nandy S, Irving M, Gordon D, Subramanian SV, Davey Smith G.Poverty, child undernutrition and morbidity: new evidence from India. Bull WHO 2005: 83: 210-216.

12. Seetharaman N, Chacko TV, Shankar SRL, Mathew $\mathrm{AC}$. Measuring malnutrition-the role of Z-scores and the Composite Index of Anthropometric Failure (CIAF). Ind J Commun. Med : 2007: 32: 35-39.

13. Mandal GC, Bose K. Assessment of overall prevalence of undernutrition using Composite Index of Anthropometric Failure (CIAF) among preschool children of West Bengal, India. Iran J Pediatr,2009: 19: 237-243.

14. Lohman TG, Roche AF, Martorell R. Anthropometric Standardization Reference Manual. Chicago:1988: Human Kinetics Books.

15. Ulijaszek SJ, Kerr DA. Anthropometric measurement error and the assessment of nutritional status. Brit $\mathrm{J}$ Nutr : 1999: 82: 165-177.

16. UNICEF. State of the World's Children Report : 2003: UNICEF, New York.
17. Bharati S, Pal M, Bharati P. Determinants of Nutritional Status of Pre-school children in India. J Biosoc Sci: 2008: 40(6):801-14.

18. Bamji M S. Early nutrition and health-Indian Perspective. Curr. Sci, 2003: 85(8), pp 1137-42.

19. Ghosh R, Bharati P. Nutritional status of adults among Munda and Pod populations in a peri urban area of Kolkata City, India. Asia Pacific Journal of Public Health: 2006: 18(2): 12-20.

20. Rao H, Rao M, Radhaiah G, et al. Nutritional status of tribal pre-school children in three ecological zones of Madhya Pradesh. Indian Pediatr: 1994: 31(6): 635-640.

21. Rice A, Sacco L, Hyder A, Black RE. Malnutrition as an underlying cause of childhood deaths associated with infectious diseases in developing countries. Bull WHO: 2000: 78: 1207-1221.

22. Rao VG, Yadav R, Dolla CK, et al. Under-nutrition and childhood morbidities among tribal preschool children. Indian Journal of Med Res: 2005: 122(1): 43-47.

23. Rao KM, Laxmaiah A, Venkaiah K, Brahmam G N. Diet and nutritional status of adolescent tribal population in nine states of India. Asia Pac J Clin Nutr: 2006 15(1): 64-71.

24. Bisai S, Bose K, Ghosh A. Prevalence of Undernutrition of Lodha Children Aged 1-14 Years of Paschim Medinipur District, West Bengal, India. Iran J Pediatr: 2008: 18(4): 323-329.

25. Fazili Anjum, Pandit MI, Mir AA, Bhat IA. Z Score and CIAF- A comprehensive measure of magnitude of under nutrition in a rural school going population of Kashmir, India. Global Journal of Medicine and Public Health: 2012: 1(5): 46-49.

26. Svedberg P. How Many People are Malnourished? Annu Rev Nutr: 2011 31: 263-83.

27. National Family Health Survey (NFHS-2), conducted in 1998-99. (www.rchiips.org/nfhs/nfhs2.shtml. accessed on 26.02.2014).

28. National Family Health Survey (NFHS-3): India Volume-1. Mumbai, India: IIPS; 2007.

29. Acharya A, Mandal G C, Bose K. Overall burden of under-nutrition measured by a Composite Index in rural pre-school children in Purba Medinipur, West Bengal, India. Anthropological Review: 2013: 76(1): 109-116.

30. Biswas S, K Bose, A Mukhopadhyay \& M Bhadra. Prevalence of undernutrition among pre-school children of Chapra, Nadia District, West Bengal, India, measured by Composite Index of Anthropometric Failure (CIAF). Anthrop. Anz. Jg: 2009: 67(3): 269-279.

31. Das Subal, Bose K. Report on 'anthropometric failure' among rural 2-6 years old Indian Bauri caste children of West Bengal. Anthropological Review: 2009: 72: 81-88.

32. Mukhopadhyay DK, Biswas AB. Food Security and Anthropometric Failure Among Tribal Children In Bankura, West Bengal. Indian Pediatr: 2011: 48: $311-$ 14. 